\title{
Chinos fronterizos: Cotidianidad y conflictos de inmigrantes chinos en Tacna y Arica (1904-1929)*
}

\section{Chinese within borders: Daily life and conflicts of Chinese immigrants in Tacna and Arica (1904-1929)}

\author{
Patricia Palma** \\ Lucas Maubert ${ }^{* * *}$
}

\section{RESUMEN}

Los inmigrantes chinos fueron uno de los grupos de extranjeros más numerosos en el norte de Chile, particularmente en las regiones de Tacna y Arica. Pese a sus aportes a la vida económica, social y cultural, los discursos políticos y de la prensa tendieron a enfatizar el peligro que significaban para el país y especialmente para esta región fronteriza. Este artículo analiza los tres grandes "peligros" que, según el discurso público, significaba la inmigración y presencia china para esta provincia: el peligro para el comercio, la salud y la nación. El estudio se sustenta en documentación del Ministerio de Relaciones Exteriores de Chile y Perú, administración chilena en Tacna y Arica, censos regionales y nacionales y artículos periodísticos.

Palabras claves: Inmigrantes chinos, comercio, salud, nación, plebiscito, Tacna, Arica.

\section{ABSTRACT}

The Chinese immigrants were one of the largest groups of foreigners in Northern Chile, particularly in the regions of Tacna and Arica. Despite their contributions to the economic, social and cultural life, political and press discourses tended to emphasize the danger that they meant for the country and especially for this border region. This paper analyzes the three great "dangers" that, according to the public discourse, Chinese immigration and presence meant for this region: the danger to the trade, public health and nation. This study is based on kept in the Ministry of Foreign Affairs of Chile and Peru, documents from Chilean administration in Tacna and Arica, national and regional censuses, and journalistic articles.

Key words: Chinese immigrants, trade, health, nation, plebiscite, Tacna, Arica.

Recibido: febrero 2021

Aceptado: mayo 2021

\footnotetext{
*Este artículo es parte del FONDECYT Postdoctoral º3190403 y del FONDECYT Regular №1190303.

${ }^{* *}$ Doctora en Historia de América Latina, University of California, Davis. Académica del Departamento de Ciencias Históricas y Geográficas de la Universidad de Tarapacá, Chile. ORCID: https://orcid.org/0000-0003-1328-9635.Correo electrónico: ppalma@academicos.uta.cl.

*** Candidato a Doctor en Historia, Universidad de Tarapacá, Chile. ORCID: https://orcid.org/0000-0001-9106-3936. Correo electrónico: maubertlucas95@gmail.com.
} 


\section{Introducción}

En febrero de 1916, el periódico El Ferrocarril de Arica daba cuenta de una "aventura chinesca" protagonizada por tres "hijos del celeste imperio", los cuales organizaron una excursión a la famosa playa La Lisera de la ciudad, y que concluyó con la movilización de la numerosa colonia china de Arica. Según lo narrado de manera jocosa por el periódico, al caer la noche y considerando que los tres chinos no regresaban de su excursión, más o menos cincuenta ciudadanos chinos, unos a pie, otros a caballo, llevando velas y faroles, emprendieron viaje a dicha playa en búsqueda de sus compatriotas, "ofreciendo un risueño espectáculo que fue contemplado por el vecindario". Los habitantes de un edificio, temerosos por el gran grupo que se acercaba, dispararon varios tiros al aire que los obligó a huir espantados y poner fin a la búsqueda de los tres ciudadanos perdidos, que según se informó habían regresado hace varias horas a sus domicilios ${ }^{1}$. La historia, narrada de manera anecdótica, ilustra varios aspectos de la experiencia de vida de los inmigrantes chinos en la ciudad. Por un lado, dejaba de manifiesto la solidaridad de la comunidad china con sus compatriotas ante eventos trágicos. Por otro, cómo en diversos momentos miembros de la comunidad fueron objeto de la burla, desconfianza y en el peor de los casos de violencia por parte de la población de la ciudad.

Al igual que en otros contextos, a fines del siglo XIX e inicios del XX, migrantes chinos hicieron contribuciones sustanciales a la sociedad chilena en áreas como la música, la gastronomía, el arte, la literatura y el lenguaje ${ }^{2}$. En las regiones de Tacna y Arica la comunidad china estableció importantes vínculos comerciales, sociales y culturales con los habitantes locales. A partir de la formación de Sociedades de Beneficencia contribuyeron en momentos de crisis económicas y desastres naturales. En Tacna, durante los años de la ocupación (1880-1929), la Sociedad de Beneficencia China fue una de las múltiples organizaciones de extranjeros que brindaron ayuda a sus compatriotas ${ }^{3}$. En Arica por su parte, en 1901 se fundó la Sociedad China "Con Wo" y en 1923 la Sociedad China "Wung Wha" por los ciudadanos chinos y sus descendientes". Estas agrupaciones realizaron importantes donaciones a la comunidad local. Por ejemplo, en septiembre de 1917 donaron 500 pesos a beneficio de los enfermos del hospital de este puerto ${ }^{5}$.

\footnotetext{
${ }^{1}$ El Ferrocarril, Arica, [en adelante EFA], 25 de febrero de 1916.

${ }^{2}$ Chang, Jason. 2017. Chino: anti-chinese racism in Mexico, 1880-1940, Champaign, University of Illinois Press, p. 6; Hu-DeHart, Evelyn y López, Kathleen. 2008. "Asian diasporas in Latin America and the Caribbean: an historical overview", Afro-Hispanic Review, Vol. 27, N 1, Nashville, p. 19.

${ }^{3}$ Panty, Oscar; Vela, Carlos; Cavagnaro, Luis y Choque Alanoca, Efraín. 2007. Nueva historia general de Tacna. Vol. II. Tacna, Gobierno Regional de Tacna, p. 64.

${ }^{4}$ Kam-Ching, Elisa. 1966. Historia de la colectividad china en Chile. Tesis para optar al título de profesora de Estado en Historia, Geografía y Educación Cívica, Universidad de Chile, p. 142; Álvarez, Sandra y Rojas, Juan. 1998. La presencia china en la ciudad de Arica durante el periodo 1885-1953. Universidad de Tarapacá, Tesis para optar al título de profesor de Educación Media en Historia y Geografía, p. 15.
}

${ }^{5}$ EFA, 14 de septiembre de 1917. 
Pese a ello, los discursos políticos y de la prensa tendieron a enfatizar el peligro que significaba la llegada masiva de inmigrantes procedentes desde China para la cultura, economía y política chilena. Chile, al igual que otros países de las Américas, no estuvo ajeno a las discusiones respecto a la necesidad de controlar, prohibir o limitar la inmigración china a su territorio. Es por ello que, si bien reconocemos que no todos los habitantes de Arica y Tacna desarrollaron sentimientos antichinos, en términos discursivos el racismo permeó a todos los grupos sociales.

Nuestra hipótesis es que en la provincia se vivió un temprano clima antichino, por tratarse de una región fronteriza que desde inicio del siglo XX siguió de cerca las políticas migratorias restrictivas peruanas y los discursos desfavorables de la opinión pública limeña respecto a esta inmigración. De este modo, los discursos locales dieron cuenta de un discurso antichino, incluso antes que las elites chilenas residentes en Santiago y Valparaíso, y el mismo gobierno discutieran sobre la necesidad de limitar su ingreso en la década de 1920. Como analizaremos en este artículo, diversos medios de prensa de la ciudad de Tacna y Arica, y autoridades sanitarias y políticas, establecieron en términos generales que la inmigración china significaba tres grandes "peligros" para Chile y especialmente a la provincia de Tacna y Arica: el peligro para el comercio, para la salud, y finalmente para la nación. Temporalmente, el estudio abarca desde 1904, año en que resurgió la inmigración china a Perú y trajo consigo la implementación de una ley en 1909 que limitó el ingreso de inmigrantes chinos a dicho país, hasta el año 1929, en que la provincia de Tacna regresó a soberanía peruana. Metodológicamente, la investigación se sustenta en un análisis exhaustivo de la documentación custodiada en el Ministerio de Relaciones de Chile y Perú, documentos emitidos y recibidos por autoridades de la Intendencia de Tacna, censos regionales y nacionales, y finalmente, artículos periodísticos publicados en los periódicos locales El Pacífico (Tacna), El Tacora (Tacna), La Voz del Sur (Tacna), El Ferrocarril (Arica) y La Aurora (Arica).

Como señala Grace Peña Delgado para el caso de los chinos fronterizos en México y los Estados Unidos, la historiografía ha analizado la inmigración china dentro de las fronteras nacionales, lo cual ha invisibilizado dinámicas propias de regiones fronterizas ${ }^{6}$. Por un lado, se ha estudiado la presencia china en los Estados Unidos, y especialmente el control de la inmigración a partir de la Ley de Exclusión China de 1882. Mientras que, en el caso de México, las investigaciones se han centrado en las primeras décadas del siglo XX, y particularmente en los años previos a la expulsión de chinos en 1931. Sin embargo, como Grace Peña ha evidenciado, las dinámicas sociales, migratorias y económicas de los chinos en las regiones fronterizas no pueden comprenderse sin adoptar una perspectiva transnacional. Sin embargo,

\footnotetext{
6 Peña, Grace. 2012. Making the chinese mexican: global migration, localism, and exclusion in the U.S.-Mexico borderlands, Stanford, Stanford University Press, pp. 3-8.
} 
esta aproximación transnacional ha sido escasamente desarrollada en otros países de América Latina con alta población inmigrante china.

Los estudios transnacionales y transfronterizos han cobrado gran importancia los últimos años, influyendo sobre la manera con que se están analizando procesos migratorios, al considerar que los migrantes elaboraron relaciones sociales múltiples entre su país de origen y sociedades receptoras, construyendo de este modo campos sociales que superan las fronteras nacionales ${ }^{7}$. Esta dimensión reviste aún más relevancia al tratarse de una zona que constituye un espacio fronterizo, donde se implementaron estructuras culturales y políticas nuevas al terminar la Guerra del Pacífico, y que permite repensar los vínculos entre nación, Estado y territorio ${ }^{8}$. Tacna y Arica era una zona de gran diversidad donde coexistían distintos grupos nacionales a la espera de un posible plebiscito de autodeterminación, donde las "otredades" contribuyeron de la formación de la identidad regional ${ }^{9}$, proceso del cual los inmigrantes chinos fueron partícipes.

En el caso de los estudios sobre inmigración china para el caso de Chile y Perú, éstos se han enfocado principalmente en espacios geográficos específicos, y desde un punto de vista legal, demográfico, económico y diplomático ${ }^{10}$. En términos geográficos, la historiografía peruana se ha enfocado principalmente en la inmigración china en Lima, y en las haciendas agrícolas del norte del país en donde existió la principal concentración de inmigrantes chinos, especialmente en el siglo $\mathrm{XIX}^{11}$. En Chile, en cambio, gran parte de las investigaciones se han enfocado en las provincias del norte del país, especialmente durante las primeras décadas del siglo XX ${ }^{12}$. En lo

\footnotetext{
7 Feldman-Bianco, Bela. 2015. "Desarrollos de la perspectiva transnacional: migración, ciudad y economía política", Alteridades, Vol. 25, n50, México, pp. 13-26.

${ }^{8}$ Appadurai, Arjun. 1996. Modernity at Large: Cultural dimensions of Globalization, Minneapolis, University of Minnesota Press.

9 Galdames, Luis y Díaz, Alberto. 2007. "La construcción de la identidad ariqueño-chilena durante las primeras décadas del siglo XX", Diálogo Andino, N²9, Arica, pp. 19-28. En otro contexto, acerca de la participación de grupos extranjeros como actores de la formación de identidades nacionales, véase: Sahlins, Peter. 2000. "La nationalité avant la lettre. Les pratiques de naturalisation en France sous l'Ancien Régime", Annales. Histoire, Sciences Sociales. Vol. 55, N5, París, pp. 1081-1108.

10 Quizás una excepción es el trabajo de Lin Chou, Diego. 2004. Chile y China: inmigración y relaciones bilaterales, (1845-1970), Santiago, DIBAM.

11 La historiografía peruana sobre inmigrantes chinos es extensa, ver entre otros: Rodríguez, Humberto. 2000. Herederos del Dragón. Historia de la comunidad china en el Perú, Lima, Fondo Editorial del Congreso del Perú; Lausent-Herrera, Isabelle. 2009. "Tusang (tusheng) and the Changing Chinese Community in Peru", Journal of Chinese Overseas, Vol. 5, № 1, Singapore, pp. 115-152; Chuhue, Richard; Li Jing, Na, y Coello, Antonio. 2012. La inmigración china al Perú: arqueología, historia y sociedad. Lima: Universidad Ricardo Palma, Instituto Confucio, Editorial Universitaria. Palma, Patricia y Ragas, José. 2018. "Enclaves sanitarios: higiene, epidemias y salud en el Barrio Chino de Lima (1880-1910)", Anuario Colombiano de Historia Social, Vol. 45, № 1, Bogotá, pp. 159-190.

12 Ver entre otros: Calle, Marcos. 2014. "Hijos del Dragón: inmigrantes chinos y su inserción socioeconómica en la provincia de Tarapacá, 1860-1940". Revista de Ciencias Sociales, N3 32, Iquique, pp. 25-62; Palma, Patricia y Montt, María. 2017. "La diáspora china en Iquique y su rol en la política de ultramar durante la República y el inicio de la Guerra Fría (1911-1950)”, Diálogo Andino, №54, Arica, pp. 143-152; González, José. 2020. “Desde la influencia del
} 
referente a los departamentos de Tacna y Arica, los trabajos son escasos, particularmente para el caso de Tacna ${ }^{13}$.

\section{Inmigrantes chinos en la frontera norte}

La elección de Tacna y Arica como lugar de estudio responde a diversos motivos. El primero, la Provincia constituyó un espacio fronterizo con dos países del norte de Chile -Perú y Bolivia-, que nos permite aprehender la dimensión transfronteriza de la circulación migratoria china en América Latina. El segundo motivo tiene que ver con el hecho de que estos territorios se encontraban en una situación diplomática particular desde el final de la Guerra del Pacífico (1879-1883). En efecto, el tratado de Ancón, que puso fin a este conflicto bélico entre estos tres países vecinos, estableció en su artículo tercero la realización de un plebiscito para definir la soberanía definitiva de Tacna y Arica. Es decir, la población local tendría que votar para mantenerse bajo la administración del Estado chileno o reincorporarse al territorio nacional peruano. Sin embargo, este plebiscito nunca fue realizado, aunque la sombra de su organización generó tensiones nacionalistas entre las cancillerías y poblaciones de Chile y Perú ${ }^{14}$.

Durante estos años de disputa, que solo fue resuelta en 1929 con la partición de los territorios en conflicto, gran parte de la población local se resistió a la implementación de la administración chilena y a las medidas tendientes a "chilenizar" estos territorios en previsión del plebiscito ${ }^{15}$. En este conflicto, locales y extranjeros se vieron envueltos en las discusiones acerca de la soberanía de los territorios, y los inmigrantes chinos no fueron la excepción como analizaremos en el último apartado.

darwinismo social hasta el imperio de los derechos humanos. Inmigración en Chile entre 1907 y 2018", Estudios de Derecho, Vol. 77, N 169, Medellín, pp. 325-348; González, José; Llanos, Claudio y Lufin Varas, Marcelo. 2020. “Tres problemáticas de la inmigración china en el norte de Chile", Si somos americanos. Revista de Estudios Transfronterizos, Vol. XX, №2, Iquique, pp.91-115; Galaz-Mandakovic, Damir y Moraga, Jorge. 2021. "Migración china en Tocopilla. Heterogeneidad relacional y transformaciones internas (Chile, 1884-1960)", Rumbos TS, N²4, Santiago, pp. 85-128; Ríos, María Elvira; Montt, María y Chan, Carol. 2021. "El imaginario de lo chino en las revistas magazinescas chilenas de principios del siglo XX", Rumbos TS, n²4, Santiago, pp. 129-150.

13 Díaz Aguad, Alfonso. 2006. "Los consulados chilenos en oriente y su participación en el proceso de inmigración china al norte de Chile (1910-1929)”, "Diálogo Andino, N²7, Arica, pp. 61-74; Díaz Aguad, Alfonso; Díaz Araya, Alberto y Sánchez Espinoza, Eugenio. 2014. "Comercio local y redes sociales de la población china en Arica y Tarapacá, Chile (1900-1930)", Interciencia, Vol. 24, № 7, Caracas, pp. 476-482; Álvarez, Sandra y Rojas, Juan. 1998. La presencia china en la ciudad de Arica durante el periodo 1885-1953. Arica, Tesis para optar al título de profesor de Educación Media en Historia y Geografía, Universidad de Tarapacá.

${ }^{14}$ González, Sergio. 2004. El dios cautivo. Las ligas patrióticas en la chilenización de Tarapacá (1910-1922), Santiago, LOM Ediciones; González, Sergio. 2008. La llave y el candado. El conflicto entre Perú y Chile por Tacna y Arica (18831929), Santiago, LOM Ediciones.

15 Palacios Rodríguez, Raúl. 1974. La chilenización de Tacna y Arica, Lima, Editorial Arica; Díaz, Alberto; Galdames, Luis y Ruz, Rodrigo. 2013. "Aymaras y plebiscitarios: los indígenas andinos, la chilenización y las identidades en la frontera cultural (Putre, 1920-1929)", Si Somos Americanos, Vol. 13, N², Iquique, pp. 81-111. 
La provincia de Tacna presentaba otra característica peculiar. Si bien estaba bajo jurisdicción chilena, una parte importante de la población local, especialmente residentes de Tacna, se sentía parte de la nación peruana, siguiendo de cerca su legislación y replicando discursos provenientes desde Lima. Durante las primeras décadas del siglo XX, la legislación peruana y chilena distaba mucho en lo referente a la inmigración china. En el caso de Perú, en 1874 el gobierno firmó el Tratado de Amistad, Comercio y Navegación con China que garantizaba a los ciudadanos de ambos Estados la protección de sus personas y bienes. Este tratado también previó la libertad de circulación, así como la libertad de fijar residencia bajo la modalidad de migración libre y voluntaria ${ }^{16}$. Dicho periodo de inmigración libre finalizó en el año 1909 a consecuencia de los graves motines populares sucedidos en mayo en la capital, protagonizados por sectores populares que reclamaban por los altos niveles de cesantía, carestía en los artículos de primera necesidad, y especialmente por el incremento de la inmigración china, a quienes se los acusaba de ser un peligro para los trabajadores, aumentar los precios y generar cesantía al emplearse por un salario menor que el del trabajador local ${ }^{17}$. La violencia escaló hasta generar ataques a los negocios y personas de origen chino.

Con el fin de tranquilizar a la población en medio de una ola de violencia urbana, el 14 de mayo de 1909, el presidente Augusto Leguía suspendió la inmigración de ciudadanos chinos sin ocupación, es decir, inmigrantes que buscaban conseguir trabajo. La ley, que se decretó en un ambiente altamente hostil hacia los inmigrantes chinos, fue celebrada en casi todo el país, incluso en la Provincia de Tacna. Por ejemplo, el periódico La Voz del Sur de esta ciudad señalaba que la resolución que prohibía la inmigración china "era digna de aplauso, la ha tomado el gobierno interpretando el sentimiento nacional"18. En las siguientes semanas, este tipo de noticias aparecieron de forma habitual en la prensa de Tacna. Otro artículo publicado en junio, titulado "Un bien para el Perú", daba cuenta de la satisfacción con que había sido tomada la noticia, pues "los chinos, que durante largos años han pululado en el Perú como en casa propia [...] han comenzado a emigrar del país, a alejarse de nuestro suelo, en el cual ya no puede vivir, porque nosotros, los dueños de casa, no lo queremos y los expulsamos como elementos malsanos y peligrosos"19. Los años siguientes, las políticas migratorias se tornaron más restrictivas, y para 1930 el gobierno había decretado la suspensión de toda inmigración asiática, aunque fueran ciudadanos peruanos y tuvieran familias en Perú20.

\footnotetext{
${ }^{16}$ García-Corrochano, Luis y Tang, Rubén. 2011. Las relaciones entre el Perú y China, Lima, Pontificia Universidad del Perú.

17 Ruiz, Augusto. 2000. "Los motines de mayo de 1909. Inmigrantes y nativos en el mercado laboral de Lima a comienzos del siglo XX", Boletín del Instituto Francés de Estudios Andinos, Vol. 29, №2, Lima, pp. 173-188.

${ }_{18}$ La Voz del Sur, Tacna, [LVS], 15 de mayo de 1909.

19 LVS, 26 de junio de 1909.

20 McKeown, Adam. 1996. "Inmigración china al Perú, 1904-1937: exclusión y negociación”, Histórica, Vol. 20, № 1, Lima, pp. 83.
} 
A diferencia de Perú, el gobierno chileno nunca decretó la prohibición legal de los inmigrantes asiáticos al país. Si bien el ejecutivo nunca tuvo una determinación de prohibirla, se intentó controlar mediante la implementación de medidas restrictivas. Por ejemplo, en 1914 el gobierno comenzó a exigir certificado de salud, al año siguiente estableció un precio de 10 libras por las solicitudes de visa en sus consulados en Asia, mientras que a otros inmigrantes ni siquiera se les solicitaba pasaporte. En 1921, a estos requisitos se agregó un depósito de US\$185 dólares con el fin de proveer el posible regreso del portador a China. A ello se sumó la imposición de cuotas de inmigración, que para 1917 alcanzaba los 90 por año, aunque las protestas llevaron a que en los años siguientes esta cuota fuera en disminución ${ }^{21}$. Pese a estas trabas, no existió una prohibición de su ingreso al país, a diferencia de lo que sucedía en Perú.

Esta desigualdad en las políticas migratorias sin duda impactó en la circulación de inmigrantes chinos procedentes de Perú hacia Chile, y especialmente en las regiones de Tacna y Arica, las más próximas a Perú. Esta reconfiguración migratoria en el espacio fronterizo producto de la legislación restrictiva peruana hacia los inmigrantes chinos puede observarse en el análisis demográfico de los censos nacionales y regionales levantados en la Provincia. El peak de población china en el departamento ocurrió entre 1907 y 1914, coincidente con la política inmigratoria antichina del gobierno de Augusto Leguía en Perú. Desde que el Estado chileno comenzó a ocupar la Provincia de Tacna en 1880, los residentes chinos constituían una de las colonias extranjeras más numerosas. El censo realizado en 1885 indicó que en la provincia residían 296 individuos procedentes del Celeste Imperio, formando la cuarta colonia extranjera más numerosa. Sin embargo, si se descartan los extranjeros fronterizos - peruanos y bolivianoslos chinos conformaban el segundo grupo más importante, solo detrás de la comunidad italiana. Estos se distribuían de manera más o menos homogénea entre las ciudades de Tacna y Arica. El 56,08\% de ellos vivían en el departamento de Tacna (166), mientras que los restantes ciento treinta ciudadanos chinos lo hacían en Arica ${ }^{22}$.

El censo realizado en 1907 evidenció una importante disminución de dicha comunidad en la zona, cayendo en el quinto lugar con tan solo 92 individuos, repartidos equitativamente entre Tacna (48) y Arica (44). Esta situación respondería a una baja global de la población en la zona posterior a la Guerra del Pacífico, según consta el censo de 1895. El descenso poblacional y comercial en la Provincia incitó a muchos extranjeros residentes de la zona a establecer su residencia en otras regiones y moverse hacia el sur, particularmente a la región de Tarapacá, cuya creciente actividad salitrera atrajo a migrantes provenientes de numerosas regiones del

\footnotetext{
${ }^{21}$ Lin Chou. 2004. Chile y China..., pp. 201-211.

22 Dirección Central de Estadísticas. 1889. Sesto Censo Jeneral de la población de Chile levantado el 26 de noviembre de 1885 y compilado por la Oficina Central de Estadística en Santiago. Tomo Segundo, Valparaíso, Imprenta de "La Patria", pp. 438-439.
} 
mundo. En consecuencia, los censos indican una redirección de la población china en Tarapacá, la cual casi se duplicó entre 1895 y $1907^{23}$.

Gráfico 1. Evolución de la cantidad de residentes chinos en la provincia de Tacna (1885-1930)

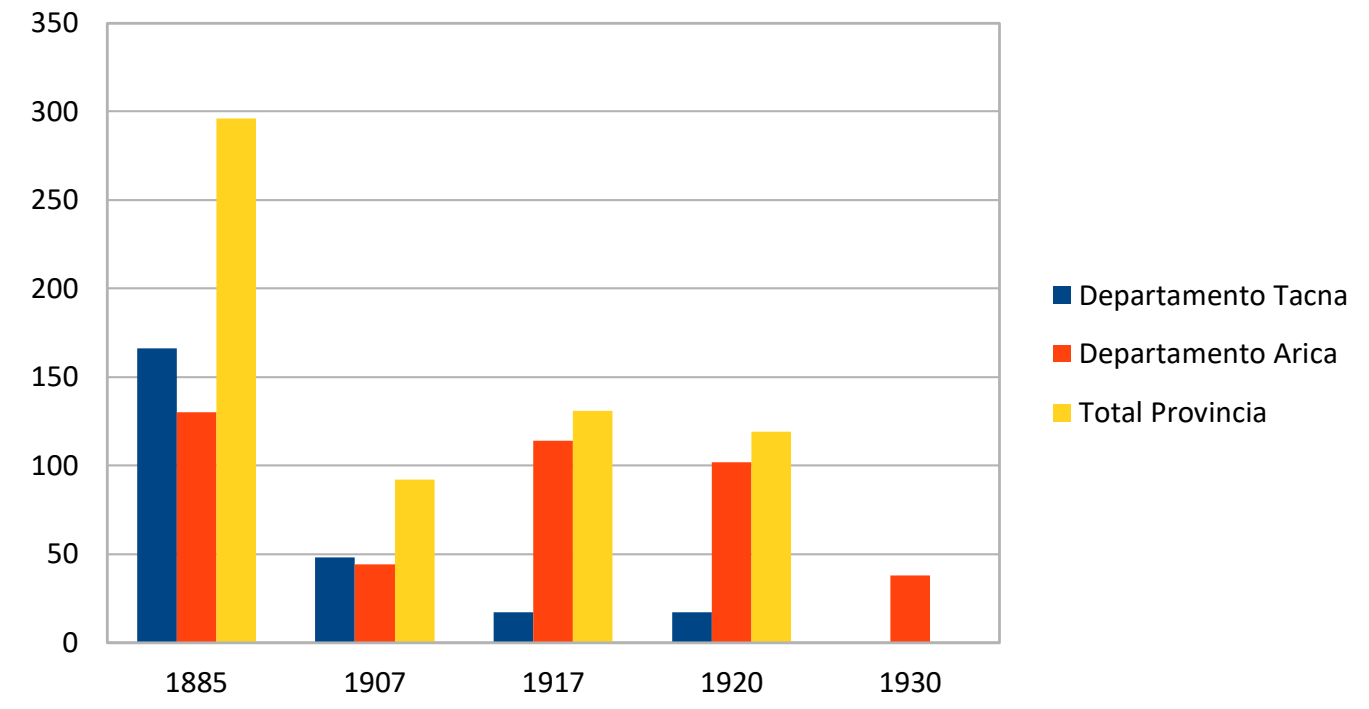

Fuente: Elaboración propia a partir de los Censos Generales de la República de Chile, 1885, 1907 y 1920; Archivo Histórico Vicente Dagnino, Universidad de Tarapacá, Arica, Chile, Fondo Intendencia de Tacna y Gobernación de Arica [en adelante, AHVD], Censos del Departamento de Arica y del Departamento de Tacna, 1917.

Además de los censos nacionales realizados por el Estado chileno cada diez años, durante las primeras décadas del siglo XX se llevaron a cabo censos regionales con el fin de dimensionar la intención de voto de la población local ante un posible plebiscito. Estos catastros poblacionales a nivel regional permiten, al contrastarlos con las encuestas nacionales, apreciar de manera gráfica la evolución de las colonias extranjeras en el extremo norte del país en las primeras décadas del siglo XX24. El censo regional realizado en 1917 constituye una fuente documental muy valiosa para dar cuenta de los cambios de patrones migratorios chinos. Por un lado, destaca una nueva llegada de inmigrantes procedentes del otro lado del Océano Pacífico, ya que la cantidad de residentes chinos alcanzó los 131 individuos, un alza de 42,39\% en una década, elevando la colonia china al tercer lugar entre las comunidades extranjeras, siendo la italiana la más numerosa en la provincia. Cabe destacar que este censo confirma una tendencia de la inmigración china predominantemente masculina $(95,42 \%)$ y de solteros $(72,8 \%)$, patrón

\footnotetext{
${ }^{23}$ Díaz et. al. 2014. Comercio local y redes sociales... pp. 478-479; Calle, Marcos. 2014. Hijos del Dragón... pp. 34-37. ${ }^{24}$ Pinto, Jorge. 2015. Los censos chilenos del siglo XX. Temuco, Ediciones Universidad de la Frontera, pp. 49-50.
} 
migratorio que se repitió en América Latina ${ }^{25}$. Por otro lado, da cuenta de un cambio a escala regional. A diferencia de los catastros anteriores donde existía una repartición más o menos equitativa entre Tacna y Arica, este censo dejó en evidencia que la mayoría de los chinos residentes en la Provincia lo hacían en el Departamento de Arica $(82,07 \%)$, casi la totalidad en su zona urbana ${ }^{26}$.

Una de las explicaciones a este desequilibrio migratorio en la provincia, que llevó a varios inmigrantes chinos residentes en Tacna moverse a Arica, tendría relación a las políticas antichinas llevadas a cabo por el gobierno peruano, implementadas desde 1909. El cierre de puertas hacia la inmigración china en Perú estuvo acompañado de un clima de hostilidad racial hacia estos inmigrantes. Si bien la historiografía peruana no ha analizado la presencia china en Tacna, es posible plantear que el clima antichino llegó hasta dicha ciudad, lo que se puede observar en los periódicos locales La Voz del Sur y El Tacora. Estos periódicos, al igual que sus pares limeños, habían responsabilizado a la comunidad china por la propagación de enfermedades como la peste bubónica de 1903-1904 y aplaudieron medidas abiertamente hostiles hacia la comunidad china residente en el país, como la destrucción del llamado Callejón Otaiza de Lima en $1909^{27}$.

Las autoridades chilenas de la provincia intentaron reducir la cantidad de inmigrantes chinos, pese a que el país no contaba con una legislación similar a su par peruano de control migratorio. Así lo demuestra un oficio del Gobernador de Arica, Luis Arteaga a Carlos Castro Ruiz, Subsecretario del Ministerio de Relaciones Exteriores en agosto de 1914. En esta carta, Arteaga respondía una misiva en la que al parecer se le solicitaba disminuir el número de inmigrantes chinos en la ciudad, señalando que: "La obra tiene sus dificultades serias, pues los chinos han aparecido con una cantidad de protectores que no me imaginaba, sin embargo, espero que en el plazo de 6 meses queden reducidos á 20 el número de mas de 150 chinos que hay en esta ciudad" ${ }^{28}$. Esto demostraría que, por un lado, existía un discurso por parte de las autoridades chilenas que permitía la inmigración libre de ciudadanos chinos, pero que, en la práctica, las autoridades nacionales y regionales de manera confidencial discutían la mejor forma de reducir y limitar esta inmigración.

Este anhelo de la autoridad local ariqueña parece haber tenido resultado, ya que el censo de 1917 indica una reducción en el número de ciudadanos chinos en el Departamento, a tan solo 114, tendencia que se mantuvo en los años siguientes. En el censo de 1920 se observa una

\footnotetext{
${ }^{25}$ Calle. 2014. Hijos del dragón... p. 34; Hu-DeHart, Evelyn. 2002. "Los chinos del norte de México, 1875-1930: la formación de una pequeña burguesía regional", en Magaña Mancillas, Alberto (ed.), China en las Californias, Tijuana, Editorial Conaculta, Centro Cultural Tijuana, pp. 11-44; López, Kathleen. 2013. Chinese cubans: a transnational. History. Chapel Hill, University of North Carolina Press., pp. 9-16.

${ }^{26}$ AHVD, Censo del Departamento de Tacna y Censo del Departamento de Arica, 1917.

27 LVS, 9 de mayo de 1903; El Tacora (Tacna), 13 de mayo de 1909; Palma y Ragas. 2018. Enclaves sanitarios... pp. 178-179.

${ }^{28}$ AHVD, Vol. 45. Oficio reservado del 4 de agosto de 1914, f. 109.
} 
nueva baja contabilizando 102 individuos de nacionalidad china en el puerto ariqueño ${ }^{29}$, mientras que, en Tacna, la población china se mantuvo a niveles bajos en las primeras décadas del siglo XX. Sin embargo, es necesario tener en consideración que esta cifra solo incluye a los inmigrantes procedentes desde China, los cuales iban disminuyendo por dejar la ciudad, pero principalmente por defunciones. El censo no contabiliza a la segunda generación de chinos (o Tusangs) que fueron en aumento durante dicho periodo, y que al igual que sus padres mantuvieron muchas de sus costumbres, especialmente el comercio como principal actividad laboral, como analizaremos a continuación ${ }^{30}$.

\section{¿Un peligro para el comercio? Una posición destacada y criticada}

La nueva generación de inmigrantes chinos, que se instaló en la provincia a inicios del siglo XX, lo hizo con el fin de ejercer principalmente actividades de carácter comercial. Durante estos años, el puerto de Arica parece haber ofrecido condiciones propicias para sus negocios, por su situación portuaria y el tránsito de mercaderías generado por la construcción y posterior funcionamiento del ferrocarril de Arica a La Paz, explicando por qué dicho puerto se convirtió en el epicentro de la presencia china en la provincia. Esta línea ferroviaria, producto del Tratado de Paz y Amistad suscrito entre Bolivia y Chile en 1904, atrajo una gran cantidad de obreros chilenos para su construcción -entre 1907 y 1913- y constituyó un punto de fricciones diplomáticas entre ambos países para el caso de la migración china con destino al país altiplánico. En efecto, las autoridades chilenas se quejaban de que inmigrantes chinos que desembarcaban en el norte declarando ir a Bolivia se quedaban clandestinamente en Chile, por lo que implementaron medidas tendientes a limitar este flujo migratorio ${ }^{31}$.

Con el paso de los años, los inmigrantes chinos se constituyeron en una de las colonias esenciales en cuanto a la actividad económica local, junto a la colonia italiana ${ }^{32}$. Este hecho tiene relación con un cambio relativo a la composición de la colonia en la región, ya que se observa que la mayoría de los chinos de la zona orientaron su actividad laboral hacia el comercio. Efectivamente, el censo de 1885 muestra que la mayoría de los chinos que residían en Arica ejercían oficios de carniceros y $\operatorname{cocineros}^{33}$, mientras que el catastro 1917 señala que

\footnotetext{
${ }^{29}$ El censo de 1930 dio cuenta de una disminución más significativa aún, al contabilizar solamente 38 in dividuos de nacionalidad china en el puerto ariqueño. No obstante, es difícil evaluar si este fenómeno tuvo que ver con la política migratoria anti-china o con una emigración producto de la profunda crisis económica del 1929.

30 Álvarez y Rojas. 1998. La presencia china en la ciudad de Arica..., pp. 33-34.

31 "Legación de Chile en Francia, Italia y Japón", 1919, República de Chile, Ministerio de Relaciones Exteriores. Archivo General Histórico (MRREE-AGH), Santiago, Fondo Histórico, vol. 760, 9 abril 1919, sin folio.

32 Díaz, Alfonso. 2000. Presencia italiana en la ciudad de Arica: 1885-1950. Arica, Ediciones Universidad de Tarapacá; Díaz, Alfonso y Pizarro, Elías. 2017. "Estrategias políticas de organización, integración e identidad de una colonia extranjera en una región de frontera: italianos en el extremo norte de Chile (1880-1930)", Dilemas Contemporáneos: Educación, Política y Valores, Vol. 5, N 1, Toluca, pp. 1-28.

${ }^{33}$ Dirección Central de Estadística. 1889. Sesto Censo Jeneral..., p. 451.
} 
la mitad de los chinos residentes en la provincia ejercían como comerciantes (66 de 131). De ellos, su gran mayoría se dedicaron a dirigir pequeños negocios de abarrotes o almacenes al por menor, y aquellos que trabajaban de manera dependiente lo hacían en tiendas cuyos dueños eran de su misma nacionalidad. Por lo tanto, para el periodo 1885-1920 hubo dos cambios fundamentales en cuanto a la composición de la colonia china en la provincia de Tacna: el primero de orden geográfico, al considerar al puerto de Arica como lugar preferencial para su instalación, el segundo de carácter laboral, con una transición del rubro servicios hacia la actividad comercial. No es de extrañar que el Directorio Internacional de Negocios Chinos publicado en California en 1913 incluyera cuatro establecimientos en Arica, todos ellos enfocados en la venta de mercaderías ${ }^{34}$.

Otro hecho característico de los inmigrantes chinos en la región es que solían mantener sus comercios al interior de su comunidad. Muchos contrataban como administradores a sus paisanos y al momento de vender sus negocios preferían hacerlo a alguno de sus compatriotas. Numerosos avisos en los diarios ilustraron este fenómeno. Por ejemplo, en 1922 Bernardino Wong informaba ser el nuevo propietario de la tienda ubicada en Atahualpa esquina Blanco Encalada, № 499 "despacho que perteneció a don Mariano Yau” ${ }^{35}$. Además de las múltiples tiendas de abarrotes, invirtieron en el establecimiento de restaurantes y hoteles, como se observa en la publicidad del Hotel Nacional, situado en la calle Dos de Mayo en Arica: “Comida de primer orden. Alojamiento higiénico, para pasajeros y familias. Instalación nueva de piezas y camas. Servicio esmerado. Precios módicos. Atendido por sus propios dueños. Francisco Chia y Moises Wong" 36 .

Las primeras décadas del siglo XX estuvieron marcadas por ataques dirigidos hacia las comunidades asiáticas, en particular a la china, mediante campañas desfavorables a través de los periódicos en Chile y América Latina. En Chile, los medios de prensa se hicieron a menudo eco del racismo y de la xenofobia imperantes en el país, y la prensa tacno-ariqueña no estuvo ajena a este fenómeno ${ }^{37}$. La posición importante adquirida por la comunidad china en el comercio local generó un aumento del número de artículos críticos a las actividades comerciales de esta comunidad en la Provincia. En diversos momentos se hicieron llamados a no comprar en estos negocios, como sucedió en 1915, cuando diversos panaderos del puerto hicieron circular un aviso "a fin de boicotear al elemento chino poseedor de pulperías donde se

\footnotetext{
${ }^{34}$ Kin, Wong (comp.). 1913. International Chinese business directory of the world. San Francisco, International Chinese Business Directory Co., p. 1327.

${ }^{35} \mathrm{EFA}, 3$ de enero de 1922.

${ }^{36}$ EFA, 6 de febrero de 1922.

${ }^{37}$ Cabe recalcar que de 1911 a 1925 todos los periódicos de la zona eran pro-chilenos, ya que las publicaciones properuanas como La Voz del Sur o El Tacora fueron clausuradas. Panty Neyra, Oscar. 1999. Historia de la prensa escrita en Tacna. Tacna, Edit. Javier Flores Arocutipa, p. 66.
} 
expende pan"38. El boicot era en respuesta al supuesto aumento indebido del precio de este artículo de primera necesidad por parte de los tenderos chinos. Sin embargo, la colonia china no guardó silencio, y utilizando igualmente la prensa se defendieron de estas acusaciones consideradas como calumniosas, criticando a los panaderos por la mala calidad y carestía del pan que se expendía al público ${ }^{39}$.

Tal parece que los más perjudicados por este episodio resultaron siendo los propios panaderos. Producto de este incidente se estableció una Panadería Asiática, propiedad de Genaro Gim, con el objetivo de entregar un pan más barato y de mejor calidad, lo cual fue aplaudido por la misma prensa, la cual agradeció "a los comerciantes chinos que han aliviado la situación del pueblo, que quisieron explotar unos cuantos inescrupulosos" ${ }^{40}$. No obstante, este episodio no bastó para detener los ataques en contra del comercio chino. Los periódicos del extremo norte criticaban frecuentemente la posición dominante e influencia adquirida por la colonia china en el comercio local, sobre todo en la década de 1910. Esta influencia fue considerada como un argumento en ciertos sectores de la opinión pública para limitar la inmigración asiática en la región:

"Se hace notar que los asiáticos, después de afluir en gran número a Norte América, donde se han implantado en su contra numerosas medidas restrictivas, han venido corriéndose a lo largo del litoral del Pacífico hacia Chile. En Méjico y el Perú, han llegado por miles y han creado trust comerciales e industriales, que han constituido la ruina de los pequeños comerciantes nacionales y han abatido los salarios"41.

Junto con lamentar la gran presencia de ciudadanos chinos en el comercio local, los periódicos solían criticar el funcionamiento de dichos negocios. Se les acusaba, por ejemplo, de que sus establecimientos eran simples fachadas escondiendo actividades ilegales, como tabernas o garitos: "sin mas patente que el de peluquería o pulpería y de dulcería, patentes que no corresponden ni siquiera a los que es ni negocio ni medianamente establecimiento, mientras tanto en ellos se juega y se descueran" ${ }^{42}$. De este modo, el descubrimiento de un garito por parte de la policía en un local supuestamente dirigido por el súbdito chino Antonio Quiun, uno de los miembros más activos de la colonia, suscitó una profunda división en el seno de la colonia asiática ariqueña. Se generó una polémica en la prensa local de varios días con otro líder de la

\footnotetext{
38 EFA, 23 de diciembre de 1915.

39 EFA, 24 de diciembre de 1915.

40 EFA, 5 de enero de 1916. Hasta la higiene de este local fue saludada por la prensa, pese a los constantes comentarios que se hacían hacia los chinos en esa materia, al constatar dos años después que permanecía "en perfectas condiciones de orden y aseo". La Aurora (Arica), 29 de abril de 1918.

41 PAC, 26 de enero de 1917. Esta retórica fue utilizada por periódicos de distintos países latinoamericanos, como el mejicano El Tráfico en Guaymas por ejemplo. Hu-DeHart. 2002. Los chinos del norte de México... pp. 24-27.

${ }^{42}$ EFA, 10 de febrero de 1917. Las cursivas son del propio artículo.
} 
comunidad, José González, éste último acusando al mencionado Quiun de desprestigiar la colonia con sus acciones ${ }^{43}$.

Otra crítica recurrente refería a precios de los artículos de consumo expendidos en los locales chinos: "todos los despacheros chinos (los únicos que abundan hoi dia en esta bendita tierra) alzaron los precios de los artículos en jeneral en un cuarenta por ciento, aparte de la merma en el peso, práctica mui comun en esta clase de comerciantes" ${ }^{\prime 4}$. Este tipo de acusaciones, en torno a una supuesta falta de honradez del comerciante chino, resurgieron durante el año 1919. Al finalizar la Primera Guerra mundial, Chile atravesó una grave crisis económica y los precios de los artículos de consumo se encontraron a niveles muy altos. Esto afectó la vida de los habitantes tacno-ariqueños, en una región en la cual el costo de la vida era superior al resto del país. Ante tal escenario, los comerciantes chinos constituyeron un chivo expiatorio ideal para explicar las dificultades coyunturales y fueron acusados de aprovecharse de la situación y de engañar al público ${ }^{45}$. La prensa local consideró que "el desprecio que manifiesta [el comercio asiático] por nuestras leyes y por nuestras autoridades, nos ha hecho levantar nuestro grito de protesta y luchar porque cese la desmoralización" ${ }^{46}$.

Estas argumentaciones presentaron importantes similitudes con otros discursos antichinos en América Latina. Al igual que en Chile, 1919 fue un año particularmente complejo para la colonia china en Lima. En el mes de mayo, en medio de una serie de protestas de trabajadores por el precio de las subsistencias, cientos de negocios chinos fueron saqueados e incendiados en las ciudades de Lima y el Callao. Esto condujo a que la Legación China en dicha ciudad iniciara una reclamación diplomática, e instruyera una investigación respecto a las pérdidas sufridas. Según la Legación, 212 comerciantes chinos sufrieron algún tipo de ataque, los cuales fueron avalados en Lp. $150.483^{47}$. Si bien el objeto de las turbas fueron los negocios chinos, los motivos iban más allá del aspecto económico. Como señala Evelyn Hu-DeHart para el caso de México, las campañas antichinas si bien tuvieron un componente económico, por lo general se formulaban y justificaban en términos legales e ideológicos, con un lenguaje ultranacionalista y racista ${ }^{48}$.

\section{¿Un peligro para la salud? Entre los perjuicios de inmoralidad y de suciedad}

A inicios del siglo XX, en Chile y el resto de las Américas se instaló en el discurso público la idea de que los asiáticos eran responsables del deterioro de la raza y la salud de la población. Estos argumentos fueron utilizados por políticos y diversos sectores de la prensa para solicitar a los

\footnotetext{
43 EFA, 28 de febrero de 1919 y 3 de marzo 1919.

44 EFA, 13 de enero de 1915.

45 EFA, 16 de agosto de 1919.

46 EFA, 23 de agosto de 1919.

47 Perú. 1920. Memoria del Ministro de Relaciones Exteriores. Lima, Imprenta Americana, pp. 20-21.

${ }^{48} \mathrm{Hu}$-DeHart. 2002. Los chinos del norte de México..., p. 24.
} 
respectivos gobiernos limitar o prohibir el ingreso de inmigrantes chinos a la región. Si bien existió un grupo de la elite chilena que defendió los beneficios económicos que significaba la llegada masiva de trabajadores baratos en áreas donde escaseaban "los brazos" como en la industria salitrera, en general, se buscó limitar su ingreso. Como señala el historiador Marcelo Sánchez, el discurso sobre el "peligro amarillo" se justificó en torno a nuevos argumentos científicos para evitar que la inmigración asiática invadiera la civilización occidental. Como señala el autor, un tópico racista era que ciertas razas, como las "amarillas", se iban a mezclar con otras puras y producir un problema para la nación ${ }^{49}$. En el caso de Chile, uno de los mayores exponentes de esta tendencia fue Nicolás Palacios, quien en su obra Raza Chilena de 1904, opinaba que el Estado no podía ceder al impulso de posibilitar "razas baratas", como "chinos, japoneses, negros o cualesquiera otros" para el beneficio económico de unos pocos, que generaban un profundo daño a la raza chilena ${ }^{50}$.

Estos tópicos racistas comenzaron a reproducirse con fuerza en la prensa de Santiago y Valparaíso y revistas magazinescas a fines de la década de 1910, y con fuerza en los años $20^{51}$. En el año 1918, por ejemplo, los periódicos El Mercurio de ambas ciudades dedicaron una serie de artículos a dar cuenta del llamado "peligro amarillo". En uno de estos artículos se aseguraba que "el chino es un peligro porque a donde va lleva sus vicios" lo cual afectaría principalmente a los obreros chilenos, pues estos no solo le disputaban "el pan al hijo de la nación" sino que también acarreaban un "desmejoramiento de la raza por el cruce con elementos inferiores" 52 . Además se los acusaba de alentar ciertos vicios dañinos para la población local, como el juego y el consumo de opio, que sumía al trabajador local aún más en su miseria ${ }^{53}$. Según estas opiniones, estos fenómenos se observaban frecuentemente en las provincias de Tacna y Tarapacá, las cuales estaban "plagadas de chinos, tanto que han llegado a constituir una verdadera calamidad pública" ${ }^{54}$.

La opinión pública de las ciudades de Arica y Tacna no estuvo ajena al discurso que señalaba los peligros de la inmigración asiática para la raza y la salud, tanto chilena como peruana, lo interesante es que este tipo de noticias comenzaron a publicarse muchos años antes que los periódicos de las elites de Santiago y Valparaíso dieran cuenta al país del supuesto problema. Por ejemplo, La Voz del Sur de Tacna celebró el cese de la inmigración china a Perú en 1909 señalando "los chinos, que durante largos años han pululado en el Perú como en casa propia,

\footnotetext{
${ }^{49}$ Sánchez, Marcelo. 2019. "Decálogo sobre migraciones para un Estado eugénico racista latinoamericano". Nuevos Mundos, Mundos Nuevos [En línea], Colloques, puesto en línea el 8 de octubre 2019, consultado el 29 de julio 2020. Recuperado de: http://journals.openedition.org/nuevomundo/77114.

50 ídem.

${ }^{51}$ Ríos et. al. 2021. El imaginario de lo chino... pp. 135-145.

52 El Mercurio, Santiago, [en adelante EMS], 15 de marzo de 1918.

53 González Pizarro et. al., 2020. Tres problemáticas..., pp. 104-108.

${ }^{54}$ EMS, 19 de agosto de 1918.
} 
malogrado nuestras razas e infestando nuestras ciudades con vicios asquerosos y enfermedades incurables" 55 . Una de las principales críticas a su arribo radicaba en que eran considerados un peligro para la salud pública. No es de extrañar que, en tiempos de epidemia, las habitaciones y locales comerciales de estos inmigrantes sufrieran del escrutinio de las autoridades. En Tacna, por ejemplo, en mayo de 1903 en medio de la epidemia de peste bubónica que afectaba a la ciudad de Lima y el vecino puerto del Callao, el Intendente de la provincia informó a la comunidad de las medidas que se debían tomar, especialmente la importancia de la desinfección de casas. A ello, el periódico La Voz del Sur agregó que la autoridad debía además desinfectar las fondas de asiáticos que existían en la ciudad, pues cada uno de los existentes en la ciudad "era un criadero de ratas, ratones y otros bichos asquerosos" como se podía apreciar en el Café del Pueblo, ubicado frente al Liceo de Tacna ${ }^{56}$.

Las denuncias sobre falta de higiene de sus locales comerciales y la venta de productos en estado de descomposición fue un tema recurrente en los diarios publicados en la Provincia. Puesto que uno de los principales rubros en que se desempeñaron los inmigrantes chinos en la región y el país fue en la venta de alimentos, las denuncias sobre la mala calidad de sus productos aparecían de forma recurrente en la prensa. Por ejemplo, en enero de 1917, El Ferrocarril de Arica denunciaba al ciudadano chino Won G. Lao, el cual, según el periódico "no contento con ser solo chino, era un perfecto cochino", pues "el local en que vive más parece cochambre que residencia de humanos" ${ }^{57}$. Las denuncias no solo se hicieron sentir en la prensa. En 1918, Washington Allendes, Subdelegado de Calana, informaba al Intendente de Tacna que los chinos comerciantes residentes en la ciudad habían comprado cerdos enfermos de triquina, los cuales eran sacrificados y llevados a la ciudad para su comercialización, lo que generaba "un gran perjuicio de la salubridad" y defraudaba los derechos municipales ${ }^{58}$.

En muchos casos, las denuncias y llamados de atención respecto a la falta de higiene se basaba en prejuicios y no en hechos comprobables. Como señalan Palma y Ragas para el caso peruano, las llamadas fondas chinas -o pequeños restaurantes- fueron objeto de una serie de prejuicios raciales, en donde la comida se utilizó como una herramienta para atacar su cultura, y presentarlos como una amenaza para la salud ${ }^{59}$. La imagen de los chinos como consumidores de ratas, o la utilización de estas y otros animales en descomposición como ingredientes de sus preparaciones, fue parte de los estereotipos tanto de la comida china como de los productos comercializados en sus negocios. Incluso, existía un rumor extendido de que utilizaban carne

\footnotetext{
55 LVS, 26 de junio de 1909.

56 LVS, 27 de mayo de 1903.

57 EFA, 12 de febrero de 1917.

${ }^{58}$ AHVD, Vol. 57. Oficio del 17 de junio de 1918, f. 79.

59 Palma, Patricia y Ragas, José. 2019. "Feeding prejudices: Chinese fondas and the culinary making of national identity in Peru", en Banh, Jenny y Liu (eds.), Haiming. American Chinese restaurants. Society, culture and consumption. Londres, Routledge, p. 49.
} 
humana en la preparación de sus guisos, que luego ofrecían a sus comensales por un bajo $\operatorname{costo}^{60}$.

Los rumores sobre la utilización de ratas en los platillos preparados en restaurantes chinos se extendieron a la ciudad de Tacna. El periódico La Voz del Sur dio a conocer con un tono jocoso, la aventura de un operario de un conocido taller de la localidad. Este hombre, al llegar a su casa y verse sin comida, "tomó una resolución valerosa, casi heroica [...] comida en una fonda de chinos". Luego de solicitar una serie de platillos, se aventuró a pedir un picadillo que tenía mal sabor. Se dispuso a examinar la carne del plato preguntando al chino su origen, el cual respondió "de colazón, señó". Ante la sospecha, el comensal decidió tomar algunos trozos y se dirigió a la Botica Italiana con el propósito de que el químico la examinara. Producto de su ausencia, el operario se dirigió al periódico "donde tras prolijo examen convenimos todos en que aquella carne no era corazón -como sostenía el chino de la fonda-ni carne humana -como lo creía nuestro chasqueado informante- sino algo más repugnante todavía: aquello, a todas luces, era icarne de rata!" ${ }^{61}$. En respuesta a esta denuncia la policía practicó algunas diligencias, pero no llegó a ninguna conclusión, pues por un lado el fondero chino negaba siquiera conocer al hombre que lo acusaba, y por otro, "el cuerpo del delito" había desaparecido. Pese a no existir certeza en la denuncia, el periódico volvió a arremeter contra el fondero, asegurando que "no es la primera vez que se sorprende a los chinos cocineros condimentando con ratas" 62.

Otros medios de prensa no estuvieron ajenos a los prejuicios antichinos y reprodujeron especulaciones en su contra en materia de salud e higiene. Así, en abril de 1915, el periódico El Pacífico informaba que a las afueras de la ciudad de forma ocasional era posible encontrar animales muertos al lado de la vía, los cuales se creía morían producto de algún mal infeccioso. Junto con informar de un hecho sin realizar las pesquisas correspondientes, y solicitar a las autoridades hacerse cargo de este problema para la salud, el periódico decidió atacar gratuitamente a la comunidad china. Esto, porque señalan de forma tendenciosa y prejuiciosa que "no sería extraño que algún chino cogiera a tales aves y las sirviera a los consumidores como pollos saltados o un guiso" ${ }^{63}$. Estas acusaciones muy rara vez llegaron a investigarse, y en la mayoría de los casos no dejaron de ser simples rumores que no disminuyeron la popularidad y concurrencia de la población local a este tipo de restaurantes o comercios administrados por inmigrantes chinos.

Finalmente, el argumento de que los ciudadanos chinos podían ingresar al país enfermedades contagiosas se repitió con frecuencia entre las autoridades políticas y del Ministerio de Relaciones Exteriores. El intendente de Tacna, el gobernador de Arica y el jefe de

\footnotetext{
60 Ídem.

61 LVS, 20 de junio de 1906.

62 LVS, 22 de junio de 1906.

${ }^{63}$ El Pacífico, Tacna, [en adelante PAC], 12 de abril 1915.
} 
la Estación Sanitaria de Arica pusieron gran empeño en impedir el ingreso al puerto de ciudadanos chinos enfermos o sin acreditar lo contrario ${ }^{64}$. Es por ello que, además de verificar sus pasaportes sanitarios, se hacía una inspección minuciosa a este grupo de extranjeros. Así lo informaba la Intendencia de Tacna, que en enero de 1925 daba cuenta al Ministro de Relaciones Exteriores haber negado el paso de chinos a Arica por no haber presentado su certificado de vacuna o sanidad, lo cual estaba en contra de los protocolos establecidos ${ }^{65}$. Los inmigrantes chinos fueron asociados a enfermedades como el tracoma y beri-beri ${ }^{66}$. En el caso del tracoma, El Mercurio de Valparaíso señalaba que si bien era una enfermedad existente en Chile, era más frecuente que la introdujeran los inmigrantes, entre ellos los chinos ${ }^{67}$. No es de extrañar que una de las enfermedades más recurrentes detectadas en la Estación Sanitaria de Arica a emigrantes chinos fuera el tracoma, como daba cuenta este periódico ${ }^{68}$.

\section{¿Un peligro para la nación? La "lealtad" china cuestionada en vista al plebiscito}

Debido al litigio diplomático entre las Cancillerías de Chile y Perú acerca de la soberanía definitiva de Tacna y Arica, la colonia china residente en los territorios en disputa se encontró en una posición ambivalente, en una región en la cual los conflictos de nacionalidades eran cotidianos entre chilenos y peruanos. En efecto, las primeras décadas del siglo XX estuvieron marcadas en la Provincia por el proceso de chilenización, y por la discusión sobre la realización de un plebiscito, estipulado en el Tratado de Ancón que en 1833 puso fin a la guerra del Pacífico, que definiría la soberanía de las ciudades de Tacna y Arica ${ }^{69}$. La población extranjera, y la china en particular, no estuvo ajena a estos fenómenos. Mientras la comunidad china era atacada de forma regular por la prensa con argumentos de carácter racista y xenófobos, al mismo tiempo se le exigía implícitamente una "lealtad" completa hacia la nación chilena, apoyando a las autoridades y, en el caso de realizarse el plebiscito, votando a favor de Chile.

Esta idea de una supuesta lealtad que debía la comunidad china hacia el Estado chileno tenía sus raíces en las acciones bélicas ocurridas durante la Guerra del Pacífico. En aquella época, Perú contaba con una gran cantidad de migrantes chinos que vivían en condiciones de semiesclavitud, también llamados coolies, cuya llegada había sido motivada por la necesidad de mano de obra en el país luego de abolida la esclavitud ${ }^{70}$. En el sur del país, existió una gran

\footnotetext{
${ }^{64}$ AHVD, Vol. 326. Oficio confidencial N¹004, 15 de octubre de 1915, f. 171.

65 MRREE-AGH, Santiago, Fondo Histórico, vol. 1046, 27 de enero de 1925, f.115.

66 El primero una infección bacteriana de fácil propagación que afecta a los ojos, y la segunda una enfermedad generada por deficiencia de vitamina $B$, en muchos casos a causa de una alimentación insuficiente.

67 El Mercurio, Valparaíso, [en adelante EMV], 4 de octubre de 1916 y 20 de mayo de 1916.

68 EMV, 22 de agosto de 1915.

${ }^{69}$ González, Sergio. 2008. La llave y el candado..., pp.13-40.

${ }^{70}$ Stewart, Watt. 1951. Chinese Bondage in Peru: A history of the chinese coolie in Peru, 1849-1874, Durham, Duke University Press; Gonzales, Michael J. 1989. "Chinese plantation workers and social conflict in Peru in the late
} 
presencia de estos trabajadores que se desempeñaban en las guaneras o en las haciendas de los valles peruanos. Durante el conflicto bélico entre Chile y Perú, el ejército chileno vio el potencial que tenía sumar a sus fuerzas a los coolies chinos.

A medida que el ejército chileno conseguía adentrarse en territorio peruano, se encontró con grandes cantidades de estos inmigrantes chinos, que seguían ejerciendo sus labores en las haciendas del sur y que se sumaron a sus filas, ayudando a la avanzada del ejército o involucrándose directamente en las acciones bélicas. Diversas fuentes chilenas coincidieron en relatar un "juramento de los chinos" ocurrido en 1881 en Lurín, señalando que los participantes eran coolies que buscaban vengarse de los tratamientos que habían sufrido ${ }^{71}$. Sin embargo, como señala la historiadora Heidi Tinsman, el juramento de Lurín no consistía fundamentalmente en ofrecer lealtad hacia Chile sino en una oportunidad para luchar contra la explotación de los coolies, viendo a los chilenos como "aliados estratégicos"72. Centenares de chinos participaron de las decisivas batallas de Chorrillos y Miraflores y muchos se convirtieron en veteranos del ejército chileno, participando en los actos patrióticos conmemorativos de la contienda ${ }^{73}$.

Estos hechos contribuyeron a la construcción de un relato nacional en Chile sobre una supuesta lealtad de estos súbditos durante la Guerra del Pacífico, la cual, en opinión de diversos sectores de la opinión pública, debía permanecer a la hora de zanjarse el litigio pendiente sobre los territorios de Tacna y Arica. En Perú, en cambio, la comunidad china debió hacer frente a una serie de hostilidades por parte de la población local, al ser acusados de traidores a la causa peruana. Varios historiadores del país al narrar el conflicto han señalado que los coolies "desataron motines y revueltas contra sus opresores"74. Esta imagen se repitió por muchos años en las crónicas peruanas de la guerra. Sin embargo, en los últimos años jóvenes historiadores -especialmente vinculados a la comunidad china- han intentado contextualizar el actuar de cierto sector de los inmigrantes chinos durante el conflicto, resaltando además el patriotismo manifestado por esta comunidad en otros episodios en que han aportado a la defensa del país en los últimos 150 años $^{75}$.

Al finalizar la Primera Guerra Mundial en 1918, resurgieron fuertes fricciones nacionalistas entre Chile y Perú, lo que obligó a ambos países a retirar sus representantes consulares e hizo temer nuevas represalias en diversos medios de prensa internacionales. Estos acontecimientos

Nineteenth Century", Journal of Latin American Studies, Vol. 21, №3, Cambridge, pp. 385-424; Meagher, Arnold. 2008. The coolie trade: the traffic in Chinese laborers to Latin America 1847-1874, Philadelphia, Xlibris Corporation.

${ }^{71}$ Tinsman, Heidi. 2018. "Rebel coolies, citizen warriors and Sworn Brothers: The Chinese loyalty oath and alliance with Chile in the War of the Pacific", Hispanic American Historical Review, Vol. 98, N³, Durham, pp. 439-469.

72 Ídem.

73 Lin, Chou. 2004, Chile y China..., p. 152.

74 Panty Neyra et. al. 2007. Nueva historia..., p. 44.

${ }^{75}$ Chuhue et. al. 2012. La inmigración china al Perú..., pp. 129-134. 
pusieron en pausa las discusiones diplomáticas sobre una eventual solución diplomática del problema de Tacna y Arica. En las provincias del norte de Chile, en varias oportunidades la "cuestión asiática" tuvo relación con la proximidad con el Perú, pues el país vecino contaba con mayor población proveniente del Celeste Imperio. En el clima de conflicto que imperaba en el norte chileno, los peruanos, tal como los asiáticos, eran asimilados a plagas, considerando que "el chino de América es el peruano", un peligro que debía frenarse en la región ${ }^{76}$. Ambos inmigrantes eran vistos con sospechas. Ante un rumor publicado en El Ferrocarril de Arica acerca de la posible incorporación de ciudadanos chinos en las filas del ejército peruano, el diario ariqueño consideró que "choca la actitud desleal e insolente de los asiáticos porque deben recordar que la Colonia China de Lima fué defendida durante la Guerra de 1879 por el propio ejército chileno, contra el vandalismo de los peruanos"77.

Los súbditos chinos y sus familias que vivían en Tacna y Arica tuvieron que lidiar con los frecuentes enfrentamientos nacionalistas entre chilenos y peruanos. Por ejemplo, en diciembre de 1918, el periódico El Deber de Arequipa informaba que en el transcurso de manifestaciones llevadas a cabo en la ciudad de Arica se habían atacado varias casas y establecimientos cuyos dueños eran peruanos. Entre los afectados estuvo el ciudadano chino Manuel Alay, a quien los manifestantes habían vandalizado su bodega ${ }^{78}$. No queda claro si fue un ataque racista por su nacionalidad, o por tener simpatías a la causa peruana. El mismo artículo hace mención a que el almacén de abarrotes del súbdito peruano José Yanulaque, ubicado en la calle 2 de mayo esquina con General Lagos, sufrió daños durante las marchas y su propietario tuvo que dejar la ciudad. Este negocio fue arrendado posteriormente por Emilio Chong. Chong, con el objetivo de evitar incidentes nacionalistas y distanciarse del antiguo dueño del local, al parecer persona non grata ante ciertos grupos chilenos, publicó un aviso en la prensa informando del cambio de dueño del local, explicitando que "nada tengo que ver con los negocios que haya hecho el señor Yanulaque"79. Estos ejemplos demuestran que los chinos no pudieron mantenerse al margen de los conflictos de orden político nacionales e internacionales que azotaron la región, y que tuvieron que lidiar con situaciones que a veces perjudicaron sus negocios, mientras que en otras circunstancias los favorecieron.

La supuesta lealtad de los inmigrantes chinos fue cuestionada por las autoridades chilenas especialmente en momentos en que se discutía el posible resultado del plebiscito. Como señalamos anteriormente, diferentes censos regionales fueron efectuados a lo largo de los años de disputa sobre Tacna y Arica. En estos se puso especial énfasis en tratar de determinar las fidelidades de los extranjeros que residían en la provincia ante un posible plebiscito. En efecto,

\footnotetext{
${ }^{76}$ EFA, 26 de abril de 1919.

77 EFA, 27 de marzo de 1920.

${ }^{78}$ El Deber, Arequipa, 27 de diciembre de 1918.

${ }^{79}$ EFA, 7 de febrero de 1919.
} 
las Cancillerías de Santiago y Lima nunca lograron ponerse de acuerdo sobre los requisitos previos de los votantes, en función del sexo, edad, alfabetismo, tiempo de residencia o nacionalidad. Por ejemplo, en la encuesta realizada a más de 3,800 residentes de Arica en 1921, los funcionarios debían determinar si las personas consultadas tenían cualidades de elector, y en el caso de ser el entrevistado extranjero, determinar "si es afecto a Chile con seguridad"80.

Después de que ambos países sometieron el litigio al arbitraje del presidente de los Estados Unidos en 1922, la posibilidad de que el árbitro ratificara la realización del plebiscito obligó a las autoridades chilenas a estar atentas a los movimientos de población en Tacna y Arica. En este marco se realizó un nuevo censo provincial en 1924, en el cual los censores tenían que sondear los antecedentes de los pobladores con el fin de evaluar sus sentimientos patrióticos, entre aquellos que eran favorables a Chile (censados como $\mathrm{CH}$ ), aquellos favorables a Perú (P) y los individuos cuya inclinación no se podía asegurar o se ignoraba (Dudosos D). Los resultados recogidos con esta encuesta sirvieron para que el gobierno chileno diseñara ocho hipótesis en vista a un futuro plebiscito, tomando en cuenta variables como la duración de residencia en la provincia o si los individuos sabían leer y escribir ${ }^{81}$. Como señala el historiador William Skuban, en función de estos modelos, entre más se restringía el cuerpo electoral - por ejemplo, al excluir los extranjeros, las mujeres o los analfabetos- más favorable se mostraba el resultado para Chile ${ }^{82}$.

El plebiscito no solo generó un control y una desconfianza de las autoridades chilenas hacia las poblaciones peruanas, sino también hacia las comunidades extranjeras residentes en los territorios en disputa. Particularmente escrutada resultó ser la colonia china, por ser una de las más numerosas y el blanco de constantes ataques de carácter racista y xenofóbico. Si nos enfocamos en la intención de voto de la colonia china, el catastro poblacional realizado en 1924 revela la dificultad con la cual las autoridades chilenas evaluaron sus fidelidades patrióticas, y la desconfianza que había hacia este sector de la población. Al considerar los hijos de chinos censados como chilenos por haber nacido en la provincia de Tacna- la revisión de los datos recopilados por los censores permite apreciar las siguientes cifras (Tabla 1).

\footnotetext{
${ }^{80}$ AHVD, Vol. 91. 1921. Índice de notas enviadas por la Intendencia de Tacna, s/f.

${ }^{81}$ Skuban, William. 2009. "La apertura y el cierre de la frontera chileno-peruana: el plebiscito de Tacna y Arica, 18801929", en Purcell, Fernando y Riquelme, Alfredo (ed.), Ampliando miradas. Chile y su historia en un tiempo global. Santiago, RIL Editores, Instituto de Historia PUC, pp. 129-158.

82 Ídem.
} 
Tabla 1: Identificación parcial de los sentimientos patrióticos de los hijos e hijos de chinos a partir el censo provincial de Tacna de 1924

\begin{tabular}{|c|c|c|c|c|c|c|}
\hline \multicolumn{2}{|c|}{} & Cantidad & Pro-Chileno & Pro-Peruano & Dudoso & Sin dato \\
\hline \multirow{3}{*}{$\begin{array}{c}\text { Departamento } \\
\text { Tacna }\end{array}$} & Chinos & 12 & 9 & 0 & 3 & 0 \\
\cline { 2 - 7 } & Hijos de Chinos & 22 & 6 & 2 & 14 & 0 \\
\cline { 2 - 7 } & Total & 34 & 15 & 2 & 17 & 0 \\
\hline \multirow{2}{*}{$\begin{array}{c}\text { Aepartamento } \\
\text { Arica }\end{array}$} & Chinos & 48 & 12 & 0 & 20 & 16 \\
\cline { 2 - 7 } & Hijos de Chinos & 27 & 3 & 2 & 10 & 12 \\
\cline { 2 - 7 } & Total & 75 & 15 & 2 & 30 & 28 \\
\hline \multicolumn{2}{|c|}{ Total Provincia } & 109 & 30 & 4 & 47 & 28 \\
\cline { 3 - 7 } & & Porcentaje & $27,52 \%$ & $3,67 \%$ & $43,12 \%$ & $25,69 \%$ \\
\hline
\end{tabular}

Fuente: Elaboración propia a partir de AHVD, Censo del Departamento de Arica, $1^{\circ}$ Subdelegación, 1924 y AHVD, Censo del Departamento de Tacna, $1^{\circ}$ Subdelegación, $1924^{83}$.

Se desprende que las autoridades chilenas no pudieron evaluar los sentimientos patrióticos de la colonia china tacno-ariqueña, ya que la gran mayoría $(68,81 \%)$ está censada como "dudosa" o los encuestadores no tenían datos que dieran luces sobre su postura. Por consiguiente, la colonia china tacno-ariqueña debió ser considerada como un grupo de riesgo para las autoridades chilenas en función de los diferentes escenarios posibles que se diseñaron para proyectar los resultados del plebiscito. Además, se puede observar que una minoría declaró explícitamente ante los censores que votaría a favor de Perú (3,67\%). Esto refleja una intención de esta comunidad de mantenerse neutral y evitar posibles conflictos con grupos nacionalistas. En efecto, Francisco Chong Chen, comerciante chino de Arica, fue anotado como prochileno, con la observación de que "dice simpatizar por Chile". Pero, en algunos casos, los agentes chilenos podían modificar la inclinación patriótica indicada si estimaban que los antecedentes conocidos del entrevistado lo justificaban. De este modo, José Santos Ordoñez Ale, hijo de chino y nacido en Moquegua, fue censado como properuano, con la observación "aunque declara su opinión favorable á Chile". Lo mismo ocurrió con Carlos Cuellar Zavalla, hijo de chino y nacido en Tacna, censado como "dudoso" pese al hecho de que "declara ser chileno".

No obstante, ciertos grupos nacionalistas peruanos también fueron escépticos y desconfiados de los inmigrantes chinos. Un episodio relatado por Manuel Portocarrero, jefe por entonces de la propaganda peruana en Arica durante la época preplebiscitaria (1925-1926), ilustra esta situación. Portocarrero narraba en sus memorias que, a fines de agosto del año 1925, en una diligencia efectuada en el valle de Azapa, ingresó a beber un refresco en compañía

83 El censo revisado es incompleto ya que sólo comprende las zonas urbanas de Tacna y Arica. Sin embargo, como pudimos ver anteriormente, la casi-totalidad de la colonia china residía en aquellas zonas. 
de otros peruanos en un establecimiento cuyo propietario era de nacionalidad china, en el cual discutieron aspectos de la campaña properuana. Al momento de despedirse:

"ingresó a la chingana el subdelegado chileno de Azapa, don Carlos Blanlot, quien con la petulancia propia de los chilenos, golpeó fuertemente con el fuete en el mostrador, dijo algunas palabras en voz baja, casi al oído, del chino conductor del establecimiento y penetró al interior, seguramente para conversar con el asiático y saber de boca de éste todos los datos relacionados con nuestra permanencia en su establecimiento y nuestra conversación con las personas anteriores nombrada. Nosotros nos despedimos y, acto seguido, tomamos el automóvil que habría de conducirnos a Arica" ${ }^{84}$.

Para este representante peruano, los inmigrantes chinos estaban al servicio de las autoridades políticas y militares chilenas, una lealtad que contrasta con la percepción que se tenía en el lado chileno. Más allá de este episodio, los dirigentes de la colonia china siempre mostraron formalmente signos de apoyo hacia los gobernantes chilenos. En 1920, en un contexto de fricción diplomática con Perú, se efectuó una erogación en el Departamento de Arica con el fin de comprar un avión para donar al Ejército chileno ante una posible movilización militar. En esta ocasión de extrema tensión nacionalista, la colonia china de Arica colaboró con un donativo de 1.695 pesos, expresando "su profundo cariño y su reconocimiento a este hermoso país, al amparo de cuyas sabias leyes vivimos tranquilos y considerados" 85 . Posteriormente, en 1922, diversos líderes de la colonia china -José González y Antonio Lópezparticiparon de un banquete efectuado en honor del ministro de Relaciones Exteriores, Ernesto Barros Jarpa ${ }^{86}$. Este mismo año, en una recepción ofrecida al nuevo ministro plenipotenciario chino en Chile, señor Out Yon King, en presencia del gobernador del departamento, el mismo José González declaró: "al pisar la tierra de este bello país, habéis visto cómo vivimos y progresamos al amparo del glorioso pabellón chileno y no puede negarse que estaréis orgulloso de la colonia residente en estas tierras" 87.

Estas muestras de apoyo, pese a la desconfianza y el desprecio de ciertos sectores de la sociedad chilena hacia la comunidad china, se concretaron cuando los líderes de la colonia china se pronunciaron formalmente a favor de Chile. En efecto, en 1925 el presidente estadounidense Calvin Coolidge rindió su laudo arbitral sobre este asunto diplomático, reiterando la necesidad de un plebiscito de autodeterminación para este territorio. De este modo, se instaló una comisión plebiscitaria, empezaron a realizarse campañas de propaganda y se abrieron registros

\footnotetext{
${ }^{84}$ Portocarrero, Manuel. 1926. Lo que vi en Arica. Lima, La Opinión Nacional, p. 24.

85 EFA, 17 de agosto de 1920.

${ }^{86} \mathrm{EFA}, 9$ de febrero de 1922.

${ }^{87}$ EFA, 21 de febrero de 1922. Según el reporte de esta reunión, el señor Yon King solicitó de sus connacionales que "fueran en toda ocasión respetuosos con las autoridades chilenas y acataran las leyes del país".
} 
electorales para poder proceder a la futura votación. Durante este proceso, los líderes de la colonia china local tuvieron que pronunciarse en cuanto a la cuestión plebiscitaria, escogiendo apoyar a Chile ${ }^{88}$. En efecto, en la imagen 1 se pueden apreciar diversos miembros de la sociedad china "Chung Wha" de Arica, con su presidente Roberto Yáñez en el centro, posando para demostrar en forma oficial su apoyo a favor de Chile, con las banderas chinas y chilenas dispuestas al fondo de la sala del club. Pese a los reiterados ataques publicados en la prensa y la desconfianza de las autoridades chilenas, los ciudadanos chinos prefirieron mantener el statu quo en vez de ser incorporados al territorio peruano.

Sin embargo, los numerosos atropellos e incidentes ocurridos entre chilenos y peruanos durante los meses previos al plebiscito hicieron que el presidente de la comisión plebiscitaria, el general William Lassister, declarara el plebiscito como impracticable en $1926^{89}$. Finalmente, en 1929, con el Tratado de Lima, los territorios disputados fueron divididos, quedando Arica bajo la soberanía chilena y Tacna siendo reintegrada al territorio nacional peruano. De este modo, el arreglo diplomático entre las Cancillerías de Santiago y Lima puso fin a una disputa de casi medio siglo que no solo afectó a chilenos y peruanos, sino que también tuvo consecuencias sobre la vida de la colonia china tacnoariqueña.

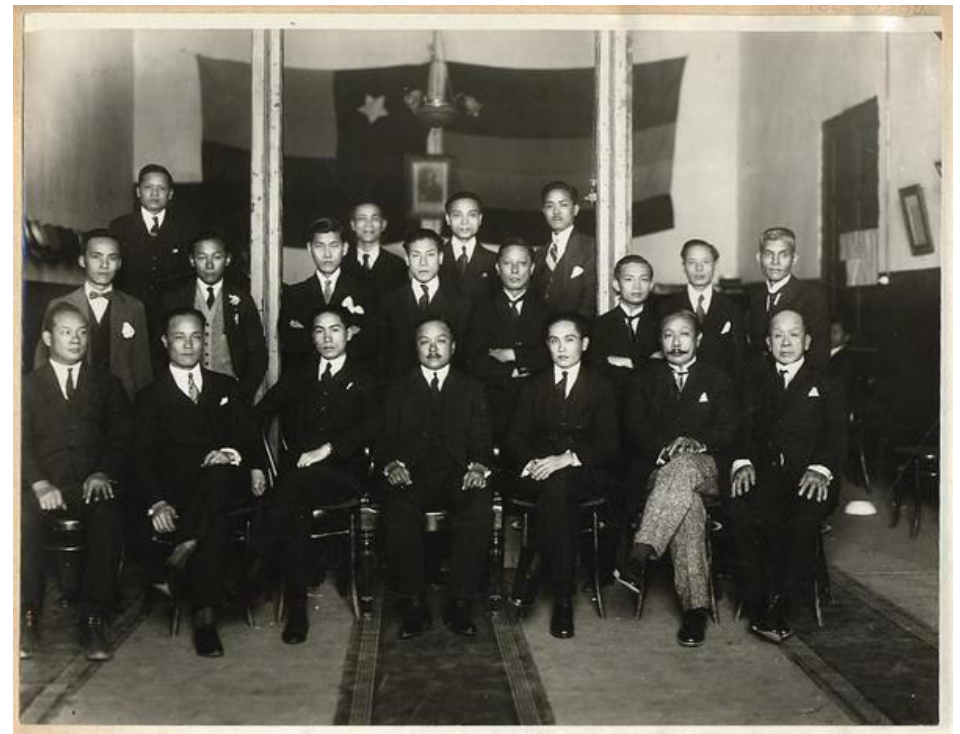

Imagen 1: Directorio de la colonia china en Arica, inscrita para votar a favor de Chile en el plebiscito ${ }^{90}$

\footnotetext{
88 En un libro pro-chileno respecto al asunto plebiscitario, José Sáenz destaca incluso la labor propagandística efectuada por algunos líderes de la colonia china, como Eugenio Mas, transcribiendo en chino las carpetas de voto a sus compatriotas e incitándolos a tomar parta a favor de Chile. Sáenz, José. 1926. Motivos plebiscitarios: iHe visto y acuso! Iquique, Imprenta y Encuadernación El Pacífico, pp. 116-120.

${ }^{89}$ González, Sergio. 2008. La llave y el candado..., pp. 104-106.

90 Disponible en: http://www.bibliotecanacionaldigital.gob.cl/bnd/635/w3-article-315552.html (Consultado el 27/07/2020)
} 


\section{Conclusiones}

En Chile a inicios del siglo XX, al igual como sucedió en otros países de América Latina, la cuestión de la inmigración asiática y de su integración a la sociedad local fue considerada como un problema de política pública. Si bien nunca se llegó al punto de prohibir esta inmigración como lo hicieron otros países -Perú, por ejemplo- hubo una clara intención de ciertas autoridades y de sectores de la opinión pública por poner trabas a la llegada de inmigrantes chinos al país. Podemos observar que la prensa regional en Tacna y Arica, al igual que numerosos otros diarios nacionales, muchas veces jugó un papel hostigador hacia la comunidad china, traduciendo un sentimiento general de desconfianza y resentimiento contra los ciudadanos chinos. Tópicos racistas y xenófobos abundaron en los artículos periodísticos, criticando costumbres consideradas como inherentes a la comunidad china, como la escasa higiene, el consumo de opio y la adicción al juego, junto con una supuesta debilidad física y racial. Este clima nacionalista también tuvo consecuencias sobre la política de las autoridades chilenas de este espacio fronterizo, las cuales trataron de limitar el flujo de inmigrantes procedentes del Celeste Imperio.

Se puede apreciar que, pese a este discurso antichino ampliamente difundido a lo largo del país, la comunidad china logró construir una posición comercial importante en la provincia de Tacna, en particular en el puerto de Arica, aunque esta influencia suscitó constantes críticas y ataques.

Las grandes crisis atravesadas por la sociedad local en las primeras décadas del siglo XX pusieron a la colonia china tacnoariqueña en una situación compleja y paradójica. En efecto, por un lado, en épocas de crisis económicas, como las ocurridas al principio y al final de la Primera Guerra Mundial, los comerciantes minoristas chinos fueron señalados como responsables de las dificultades comerciales de la población. Por otro lado, la sociedad chilena exigía de esta comunidad una suerte de lealtad hacia la causa nacional en cuanto al litigio diplomático con Perú heredado de la Guerra del Pacífico. Sin embargo, los inmigrantes chinos no fueron sujetos pasivos ante estos acontecimientos, ya que regularmente se defendían en los periódicos en contra de los artículos que los denigraban y varios de ellos tomaron partido en el asunto plebiscitario. Hubo, por lo tanto, una lucha constante de esta comunidad con el fin de ser aceptada por la sociedad chilena, pese a los prejuicios raciales y xenófobos que pesaban sobre ellos. 


\title{
Referencias citadas
}

\section{Archivos}

Archivo Histórico Vicente Dagnino (AHVD), Universidad de Tarapacá, Arica, Chile, Fondo Intendencia de Tacna y Gobernación de Arica.

Archivo del Ministerio de Relaciones Exteriores de Perú (AMRREE). Lima, Fondo correspondencia.

Archivo General Histórico, República de Chile, Ministerio de Relaciones Exteriores. Archivo General Histórico (MRREE-AGH), Santiago, Fondo Histórico.

Censos Generales de la República de Chile, 1885, 1907 y 1920.

\author{
Prensa \\ El Deber (Arequipa) \\ El Ferrocarril (Arica) \\ El Mercurio (Santiago) \\ El Mercurio (Valparaíso) \\ El Pacífico (Tacna) \\ El Tacora (Tacna) \\ La Aurora (Arica) \\ La Voz del Sur (Tacna)
}

\section{Bibliografía}

Álvarez, Sandra del C. y Rojas, Juan Pablo. 1998. La presencia china en la ciudad de Arica durante el periodo 1885-1953, Universidad de Tarapacá, Arica, Tesis para optar al título de profesor de Educación Media en Historia y Geografía.

Appadurai, Arjun. 1996. Modernity at Large: Cultural dimensions of Globalization, Minneapolis, University of Minnesota Press.

Calle, Marcos. 2014. "Hijos del Dragón: inmigrantes chinos y su inserción socioeconómica en la provincia de Tarapacá, 1860-1940”, en Revista de Ciencias Sociales, №32, Iquique, pp. 25-62.

Chang, Jason Oliver. 2017. Chino: Anti-Chinese racism in Mexico, 1880-1940, Champaign, University of Illinois Press.

Chuhue, Richard, Li Jing, Na, y Coello, Antonio. 2012. La inmigración china al Perú: arqueología, historia y sociedad, Lima, Universidad Ricardo Palma, Instituto Confucio, Editorial Universitaria.

Díaz Aguad, Alfonso. 2000. Presencia Italiana en la ciudad de Arica: 1885-1950, Arica, Ediciones Universidad de Tarapacá.

Díaz Aguad, Alfonso. 2006. "Los consulados chilenos en oriente y su participación en el proceso de inmigración china al norte de Chile (1910-1929)”, en Diálogo Andino, N²7, Arica, pp. 61-74. 
Díaz Aguad, Alfonso, Díaz Araya, Alberto y Sánchez Espinoza, Eugenio. 2014. “Comercio local y redes sociales de la población china en Arica y Tarapacá, Chile (1900-1930)", en Interciencia, Vol. 24, № 7, Caracas, pp. 476-482.

Díaz Aguad, Alfonso y Pizarro Pizarro, Elías. 2017. “Estrategias políticas de organización, integración e identidad de una colonia extranjera en una región de frontera: italianos en el extremo norte de Chile (1880-1930)", en Dilemas contemporáneos: educación, política y valores, Vol. 5, № 1, Toluca, pp. 128.

Díaz Araya, Alberto, Galdames Rosas, Luis y Ruz Zagal, Rodrigo. 2013. “Aymaras y plebiscitarios: los indígenas andinos, la chilenización y las identidades en la frontera cultural (Putre, 1920-1929)", en Si Somos Americanos, Vol. 13, № 2, Iquique, pp. 81-111.

Feldman-Bianco, Bela. 2015. “Desarrollos de la perspectiva transnacional: migración, ciudad y economía política", en Alteridades, Vol. 25, n50, México, pp. 13-26.

Galaz-Mandakovic, Damir y Moraga Reyes, Jorge. 2021. "Migración china en Tocopilla. Heterogeneidad relacional y transformaciones internas (Chile, 1884-1960)", en Rumbos TS, №24, Santiago, pp. 85128.

Galdames Rosas, Luis y Díaz Araya, Alberto. 2007. "La construcción de la identidad ariqueño-chilena durante las primeras décadas del siglo XX”, en Diálogo Andino, N²9, Arica, pp. 19-28.

García-Corrochano, Rubén y Tang, Luis. 2011. Las relaciones entre el Perú y China, Lima, Pontificia Universidad del Perú.

Gonzales, Michael J. 1989. "Chinese plantation workers and social conflict in Peru in the late Nineteenth Century”, en Journal of Latin American Studies, Vol. 21, N 3, Cambridge, pp. 385-424.

González Miranda, Sergio. 2004. El Dios cautivo. Las ligas patrióticas en la chilenización de Tarapacá (1910-1922), Santiago, LOM Ediciones.

González Miranda, Sergio. 2008. La llave y el candado. El conflicto entre Perú y Chile por Tacna y Arica (1883-1929), Santiago, LOM Ediciones.

González Pizarro, José Antonio. 2020. “Desde la influencia del darwinismo social hasta el imperio de los derechos humanos. Inmigración en Chile entre 1907 y 2018", en Estudios de Derecho, Vol. 77, № 169, Medellín, pp. 325-348.

González Pizarro, José Antonio, Llanos Reyes, Claudio y Lufin Varas, Marcelo. 2020. "Tres problemáticas de la inmigración china en el norte de Chile", en Si somos americanos. Revista de Estudios Transfronterizos, Vol. XX, N², Iquique, pp. 91-115.

Hu-DeHart, Evelyn. 2002. "Los chinos del norte de México, 1875-1930: la formación de una pequeña burguesía regional", en Magaña Mancillas, Alberto (ed.), en China en las Californias, Tijuana, Editorial Conaculta, Centro Cultural Tijuana, pp. 11-44.

Hu-DeHart, Evelyn y López, Kathleen. 2008. "Asian diasporas in Latin America and the Caribbean: an historical overview", en Afro-Hispanic Review, Vol. 27, º 1, Nashville, pp. 9-21.

Kam-Ching, Elisa. 1966. Historia de la colectividad china en Chile, Universidad de Chile, Arica, Tesis para optar al título de profesora de Estado en Historia, Geografía y Educación Cívica. 
Kin, Wong (comp.). 1913. International Chinese business directory of the World, San Francisco, International Chinese Business Directory Co.

Lausent-Herrera, Isabelle. 2009. "Tusang (tusheng) and the changing chinese community in Peru", en Journal of Chinese Overseas, Vol. 5, N 1, Singapore, pp. 115-152.

Lin Chou, Diego. 2004. Chile y China: inmigración y relaciones bilaterales (1845-1970), Santiago, DIBAM.

López, Kathleen. 2013. Chinese Cubans: a transnational. History, Chapel Hill, University of North Carolina Press.

McKeown, Adam. 1996. “Inmigración china al Perú, 1904-1937: exclusión y negociación”, en Histórica, Vol. 20, N¹, Lima, p. 83.

Meagher, Arnold J. 2008. The coolie trade: the traffic in Chinese laborers to Latin America 1847-1874, Philadelphia, Xlibris Corporation.

Palacios Rodríguez, Raúl. 1974. La chilenización de Tacna y Arica, Lima, Editorial Arica.

Palma, Patricia y Montt, María. 2017. "La diáspora china en lquique y su rol en la política de ultramar durante la República y el inicio de la Guerra Fría (1911-1950)”, en Diálogo Andino, N54, Arica, pp. 143-152.

Palma, Patricia y Ragas, José. 2018. "Enclaves sanitarios: higiene, epidemias y salud en el barrio chino de Lima (1880-1910)”, en Anuario Colombiano de Historia Social, Vol. 45, № 1, Bogotá, pp. 159-190.

Palma, Patricia y Ragas, José. 2019. "Feeding prejudices: Chinese fondas and the culinary making of national identity in Peru", en Banh, Jenny y Liu, Haiming (eds.), American Chinese restaurants. Society, culture and consumption, Londres, Routledge, pp. 44-61.

Panty Neyra, Oscar. 1999. Historia de la prensa escrita en Tacna, Tacna, Edit. Javier Flores Arocutipa.

Panty Neyra, Oscar, Vela Velarde, Carlos, Cavagnaro Orellana, Luis y Choque, Efraín. 2007. Nueva Historia General de Tacna, Vol. II, Tacna, Gobierno Regional de Tacna.

Pinto Rodríguez, Jorge. 2015. Los censos chilenos del siglo XX, Temuco, Ediciones Universidad de la Frontera.

Peña, Grace. 2012. Making the Chinese Mexican: global migration, localism, and exclusion in the U.S.Mexico borderlands, Stanford, Stanford University Press.

Perú. 1920. Memoria del Ministro de Relaciones Exteriores, Lima, Imprenta Americana.

Portocarrero, Manuel. 1926. Lo que vi en Arica, Lima, La Opinión Nacional.

Ríos, María Elvira, Montt, María y Chan, Carol. 2021. "El imaginario de lo chino en las revistas magazinescas chilenas de principios del siglo XX", en Rumbos TS, n²4, Santiago, pp. 129-150.

Rodríguez Pastor, Humberto. 2000. Herederos del dragón. Historia de la comunidad china en el Perú, Lima, Fondo Editorial del Congreso del Perú.

Ruiz, Augusto. 2000. "Los motines de mayo de 1909. Inmigrantes y nativos en el mercado laboral de Lima a comienzos del siglo XX", en Boletín del Instituto Francés de Estudios Andinos, Vol. 29, N², Lima, pp. 173-188. 
Sáenz, José. 1926. Motivos plebiscitarios: iHe visto y acuso!, Iquique, Imprenta y Encuadernación El Pacífico.

Sahlins, Peter. 2000. "La nationalité avant la lettre. Les pratiques de naturalisation en France sous l’Ancien Régime”, en Annales. Histoire, Sciences Sociales, Vol. 55, N5, París, pp. 1081-1108.

Sánchez, Marcelo. 2019. "Decálogo sobre migraciones para un Estado eugénico racista latinoamericano", en Nuevos Mundos, Mundos Nuevos [en línea], Colloques, puesto en línea el 8 de octubre 2019. Disponible en: http://journals.openedition.org/nuevomundo/77114. (Consultado el 29 de julio 2020)

Skuban, William. 2009. "La apertura y el cierre de la frontera chileno-peruana: el plebiscito de Tacna y Arica, 1880-1929", en Purcell, Fernando y Riquelme, Alfredo (ed.), Ampliando miradas. Chile y su historia en un tiempo global, Santiago, RIL Editores-Instituto de Historia PUC, pp. 129-158.

Stewart, Watt. 1951. Chinese bondage in Peru: a history of the Chinese coolie in Peru, 1849-1874, Durham, Duke University Press.

Tinsman, Heidi. 2018. "Rebel Coolies, Citizen Warriors and Sworn Brothers: The Chinese loyalty oath and alliance with Chile in the War of the Pacific", en Hispanic American Historical Review, Vol. 98, N³, Durham, pp. 439-469. 